American Journal of Infectious Diseases 3 (4): 217-224, 2007

ISSN 1553-6203

(C) 2007 Science Publications

\title{
Methamphetamine Inhibits $\beta$-Chemokines and Co-Stimulatory Molecule Expression by Dendritic Cells
}

\author{
${ }^{1}$ Madhavan P.N Nair, ${ }^{1}$ Jose W. Rodriguez ${ }^{3}$,Irina M. Borodowsky, ${ }^{2}$ Supriya Mahajan, ${ }^{1}$ Narayanan Nair, \\ ${ }^{1}$ Tolu T. Dada, ${ }^{1}$ Alain Diaz-Gonzalez, , and Paul Katz ${ }^{4}$ \\ ${ }^{1}$ College of Medicine, Florida International University, Miami Children's Hospital, Miami, Florida \\ ${ }^{2}$ State University of New York at Buffalo, NY, ${ }^{3}$ Universida Central del Caribe School of Medicine, \\ Bayamon, Puerto Rico and ${ }^{4}$ Mount Sinai Medical Center, Miami Beach, Florida
}

\begin{abstract}
The US is currently experiencing a serious epidemic of methamphetamine (Meth) use entangled with HIV-1 infection. Blood monocyte derived dendritic cells (DC) are the first line of defense against HIV-1 infection and are the initial target of HIV-1 in injection drug users. Chemokines are known to be HIV-1 suppressing molecules and are positively associated with non- progression of HIV disease. Co-stimulatory molecules are necessary for DC maturation, effective antigen presentation, cell migration, and $\mathrm{T}$ cell proliferation. Although previous studies suggest that Meth deregulates various immune responses, the role of Meth on gene expression and production of $\beta$ chemokines and co-stimulatory molecules by DC has not been studied. We hypothesize that Meth induced immune defects may be mediated by dysregulation of $\beta$-chemokines (MIP-1 $\alpha /$ CCL3, MIP$1 \beta /$ CCL4 and RANTES/CCL5), co-stimulatory and maturation molecules (CD83 and CCR7) by DC. Our results show that Meth significantly downregulates the gene expression and production of $\beta$ chemokines and co stimulatory molecule by DC from normal subjects. In HIV-1 infected subjects, RANTES variant In $1.1 \mathrm{c}$ that has been associated with accelerated HIV-1 disease progression was significantly higher compared to normal controls. Further, Meth significantly inhibited total RANTES gene expression with a reciprocal upregulation of RANTES variant In1.1c in a dose dependent manner by both immature DC (IDC) and mature DC (MDC) from normal subjects. These studies report for the first time that Meth deregulates $\beta$-chemokines and co-stimulatory molecule expression by DC. The results emanating from these studies may help to support the therapeutic application of chemokines to restore anti-HIV-1 immune responses to prevent or control HIV-1 infection in meth using populations.
\end{abstract}

Keywords: $\quad$ DC-SIGN,dendritic cell(DC) specific $\mathrm{C}$ type ICAM-3 grabbing nonintegrin,RANTES;regulated upon activation T-cell expressed and secreted;IDC immature DC; MDC, mature DC

\section{INTRODUCTION}

The US is currently experiencing a grave epidemic of methamphetamine (Meth) use as a recreational drug ${ }^{[1]}$. US Drug Enforcement Administration reports that as of May 2006, Meth use has surpassed cocaine and heroin use combined as a street or club drug. DC are the first line of defense against HIV-1 infection and are the first cellular components in the immune system to recognize any infection including HIV-1 ${ }^{[2-4]}$. Immature DC (IDC) are potent antigen presenting cells that engulf microbes and antigens. Upon interaction with antigens, DC become activated or mature and then migrate to regional lymphoid tissues where the processed antigens are presented to naive CD4 $\mathrm{T}$ cells subsequently enabling $\mathrm{T}$ cell activation ${ }^{[5-6]}$. After further maturation, DC express a number of co stimulatory molecules such as CD40, CD80 (B7.1), CD86 (B7.2) and chemokine receptor, $\mathrm{CCR} 7$ that are required for efficient antigen presentation by DC. The important role of DC as the first line of defense against HIV-1 infections has recently been recognized. Defective expression or modulation of chemokines and co stimulatory molecules by DC may cause defective antigen presentation that can then lead to defective activation of HIV-1 specific $\mathrm{T}$ cells. Chemokines have gained major attention recently because of their specific inhibitory effects on HIV-1 infection ${ }^{[7-8]}$. $\beta$-chemokines such as CCL3 (MIP-1 $\alpha$ ), CCL4 (MIP-1 $\beta$ ), and CCL5 (RANTES) are

Corresponding Author: Professor Madhavan P.N. Nair, Chair of Immunology, Florida International University, Miami Children's Hospital, 3100 SW 62nd Avenue, Miami Fl 33155 Tel: 305-663-8552 
Am. J. Infect. Dis., 3 (4): 217-224, 2007

natural ligands for the primary human immunodeficiency virus type-1(HIV-1) co receptor CCR5 and are known to block HIV-CCR5 interactions ${ }^{[9]}$. Decreased production of these chemokines may abrogate anti-HIV-1 effects facilitating HIV-1 infection. Although drugs of abuse are known to affect the immune response in general ${ }^{[10-11]}$ and specifically reduce immune responses against HIV-1 infections ${ }^{[12]}$, the role of Meth on gene expression and production of beta chemokines and co stimulatory molecules by DC from healthy, normal subjects has not been elucidated. Previous studies have shown that blood monocyte derived dendritic cells (MDDC) serve as an effective model to study HIV-1 infection in injection drug users [13-23]. Previous studies show that polymorphism in RANTES chemokine affects HIV-1 disease progression [24]. RANTES-28G mutation increases RANTES expression and delays the progression of the HIV-1 disease ${ }^{[24]}$, while RANTES In1.1C accelerates HIV-1 disease progression ${ }^{[25]}$. P. An et al ${ }^{[26]}$ showed that diminished transcription of RANTES by In1.1C regulatory allele leads to accelerated disease progression. DC produce a number of cytokines and chemokines that are essential for $\mathrm{T}$ cell differentiation and clonal expansion ${ }^{[27-28]}$. While the capacity of DC to migrate is regulated by the expression of a number of cytokines and chemokines, further activation is regulated by various co stimulatory molecules. The costimulatory molecule, CD83 which is the hallmark of mature DC (MDC) play a significant role in antigen presentation, stimulation of $\mathrm{T}$ cells and anti-HIV-1 immune responses. DC change their phenotypes and functional properties during maturation ${ }^{[29-30,31,32]}$ and CC-chemokine receptor-7(CCR7) is considered as a maturation marker for $\mathrm{DC}$ and is critically important for migration of DC to lymph nodes, in vivo function of $\mathrm{T}$ regulatory cells ${ }^{[33-34]}$. $\beta$-chemokines have gained major attention recently because of their specific inhibitory effects on HIV-1 infection ${ }^{[7-8]}$. The present study reports for the first time that Meth significantly inhibits HIV-1suppressing $\beta$-chemokines with a reciprocal upregulation of RANTES variant In1.1c. Further, Meth downregulates maturation molecule, CCR7 and co stimulatory molecule, CD83 in DC.

\section{MATERIALS AND METHODS}

Human Subjects: Blood donors were evaluated of this study and consents were obtained consistent with the policies of the National Institutes of Health. Peripheral blood samples from healthy individuals were drawn into a syringe containing heparin (20 units $/ \mathrm{ml}$ ). DC were isolated from peripheral blood mononuclear cells (PBMC) using protocols validated by Dauer et al
${ }^{[35]}$. Briefly, PBMC were separated on a density gradient and adhered to plastic culture plates in media containing serum. Non-adherent cells were removed after $1 \mathrm{hr}$ at $37^{\circ} \mathrm{C}$ and adherent cells cultured for 6 days in media containing $100 \mathrm{U} / \mathrm{ml}$ of rhGM-CSF and $100 \mathrm{U} / \mathrm{ml}$ of IL4 ( $\mathrm{R} \& \mathrm{D}$ systems, Minneapolis, MN). After 6 days of culture, IDC were removed by gently swirling the plate to resuspend them for use in the experiments. These IDC were allowed to progress to MDC by incubating for five more days with media containing $1000 \mathrm{U} / \mathrm{ml}$ of rhGM-CSF and $1000 \mathrm{U} / \mathrm{ml}$ of IL-4 as above.

FACS analysis: Phenotypic characterization of IDC and MDC was done by flow cytometry analysis. Both IDC and MDC were washed in FACS buffer (eBioscience, San Diego, CA), incubated with nonspecific IgG $(20 \mu \mathrm{g} / \mathrm{ml})$ for $10 \mathrm{~min}$ at $4^{\circ} \mathrm{C}$ to block Fc receptors, stained with specific antibodies for DC surface markers and analyzed by flow cytometry. Both MDC and IDC express CD80, CD86, CD40, HLA-DR, DQ, and CD11c at different levels. However, MDC predominantly express CD83 and CCR7 as described [33-34].

Cell culture: IDC and MDC were cultured at a concentration of $5 \times 10^{5}$ cells $/ \mathrm{ml}$ with Meth $(10 \mu \mathrm{M}$ to $100 \mu \mathrm{M})$ in 6 well plates. Meth used in the present experiments was obtained from Sigma Chemical Co (Cat\# 2222) as a lyophilized form and dissolved in culture media. The purity of Meth is $\sim 90 \%$, and it is predominantly $d$-methamphetamine which has greater CNS potency.The concentration of Meth that we have used in the experiments $(10-100 \mathrm{mM})$ were within the range that are similar to levels found in the blood, urine or tissue fluid samples of Meth using subjects( 11$147 \mathrm{mM})^{[36-37]}$.

RNA extraction: Cytoplasmic RNA was extracted by an acid guanidinium-thiocyanate-phenol-chloroform method as described ${ }^{[38]}$. Cultured DC were centrifuged and resuspended in a $4 \mathrm{M}$ solution of guanidinium thiocynate. Cells were lysed by repeated pipetting and then phenol-chloroform extracted in the presence of sodium acetate. After centrifugation, RNA was precipitated from the aqueous layer by adding an equal volume of isopropanol and the mixture was kept at $-20^{\circ}$ $\mathrm{C}$ for $1 \mathrm{hr}$ and then centrifuged to sediment the RNA. The RNA pellet was washed with $75 \%$ ethanol to remove any traces of guanidinium. The final pellet was dried and resuspended in diethyl pyrocarbonate (DEPC) water and the amount of RNA determined using a spectrophotometer at $260 \mathrm{~nm}$. DNA contamination in 
the RNA preparation was removed by treating the RNA preparation with DNAse (1 IU/ $\mu$ g of RNA) for $2 \mathrm{hr}$ at $37^{\circ} \mathrm{C}$, followed by proteinase $\mathrm{K}$ digestion at $37^{\circ} \mathrm{C}$ for 15 min and subsequent extraction with phenol/chloroform and $\mathrm{NH}_{4} \mathrm{OAc} / \mathrm{ETOH}$ precipitation. The DNA contamination in the RNA preparation was checked by including a control in which reverse transcriptase enzyme was not added in the PCR amplification procedure. RNA preparation, which is devoid of any DNA contamination, was used in the subsequent experiments in real time PCR. The isolated RNA was stored at $-70^{\circ} \mathrm{C}$ until used.

Real Time, Quantitative RT-PCR: Gene expression was quantitated using real time PCR. Relative abundance of each mRNA species was assessed using the SYBR green master mix from Stratagene (La Jolla, CA) to perform real time semi-quantitative PCR using the ABI Prism 5700 instrument that detects and plots the increase in fluorescence versus PCR cycle number to produce a continuous measure of PCR amplification. To provide precise quantification of initial target in each PCR reaction, the amplification plot is examined at a point during the early log phase of product accumulation. This is accomplished by assigning a fluorescence threshold above background and determining the time point at which each sample's amplification plot reaches the threshold (defined as the threshold cycle number or $\mathrm{C}_{\mathrm{T}}$ ). Differences in threshold cycle number are used to quantify the relative amount of PCR target contained within each tube Relative mRNA species expression was quantitated and expressed as transcript accumulation index $\left(\mathrm{TAI}=2^{- \text {delta delta } \mathrm{CT}}\right)$, calculated using the comparative $\mathrm{C}_{\mathrm{T}}$ method ${ }^{[39]}$. All data were controlled for quantity of RNA input by performing measurements on an endogenous reference gene, $\beta$-actin. In addition, results on RNA from treated samples were normalized to results obtained on RNA from the control untreated sample.

\section{RESULTS}

Meth suppresses the expression of co-stimulatory molecule, CD83 and the maturation marker, CCR7 on DC: Since the co stimulatory molecule CD83, a hallmark of MDC, plays a significant role in antigen presentation, stimulation of $\mathrm{T}$ cells and anti-HIV-1 immune responses, we examined the in vitro effect of Meth on the expression of the CD83 molecule on DC by flow cytometry analysis. Data presented in Fig. 1 show that Math significantly downregulated the expression of CD83 on MDC. The percentage positive cells expressing CD83 at Meth concentrations of 10 and
$100 \mu \mathrm{M}$, respectively were $11.3(\mathrm{p}<0.03)$ and $9.8 \%$ $(\mathrm{p}<0.009)$ compared to $16.9 \%$ in the untreated control culture.

DC change their phenotypes and functional properties during maturation $[29-30,31,32]$. Since CCR7 is a maturation marker for DC, which is critically important for migration of DC to lymph nodes and for in vivo function of $\mathrm{T}$ regulatory cells ${ }^{[33-34]}$, we examined the effect of Meth on CCR7 expression by MDC (Fig. 2a). MDC treated in vitro with Meth at a concentration of $100 \mu \mathrm{M}$ showed significantly decreased numbers of CCR7 positive MDC (2.6\%, $\mathrm{p}<0.05)$ compared to $6.9 \%$ in the untreated control culture. However, MDC treated with a lower concentration of Meth $(10 \mu \mathrm{M})$ did not show any significant change in the phenotypic expression of CCR7 positive cells $(5.7 \%, \mathrm{p}<0.06)$ compared to control culture $(6.9 \%)$. To rule out the possibility that the immunomodulatory effects induced by Meth were non specific; we examined the effects of Meth (10-100 $\mu \mathrm{M})$ on viability as well as on apoptosis by DC. Our results showed that Meth $(10-100 \mu \mathrm{M})$ did not induce apoptosis in DC as accessed by Annexin V expression by FACS analysis (2b) as well as evidenced by $>95 \%$ viability by trypan blue dye exclusion (data not presented). These results indicate that Meth use decreases the percentage of co-stimulatory molecule positive MDC in HIV-1 infected subjects and these cells likely play a significant role in the progression of HIV-1 disease by preventing the maturation of IDC to MDC.

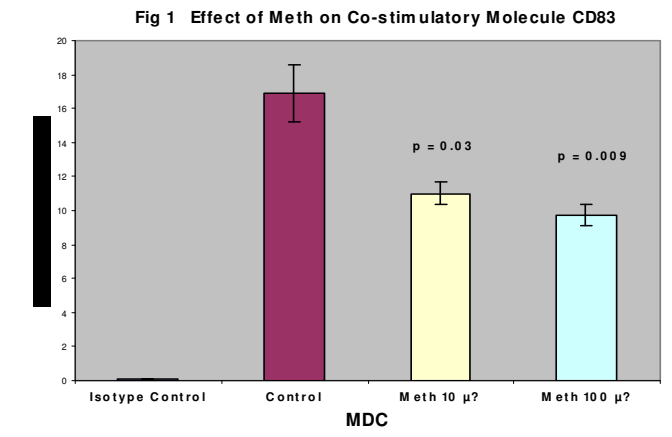

Fig. 1: Meth decreases the expression of co stimulatory molecule, CD83 on MDC. Normal MDC cultures $\left(\sim 5 \mathrm{X} 10^{5} \mathrm{cell} / \mathrm{ml}\right)$ were treated with Meth for 24 $\mathrm{hr}$ following which FACS analysis was done to determine the percentage of MDC expressing co stimulatory molecule, CD83. Statistical significance was calculated by Students' 't'-test $(n=3)$.

Effect of Meth on RANTES and its variant gene expression in IDCs and MDCs: Since $\beta$-chemokines, 
the natural ligands for HIV-1 coreceptors are also produced by DC and are known to play a significant role in the prevention of HIV-1 infection ${ }^{[7-8]}$, we investigated whether Meth treatment modulates the gene expression and production of HIV-1 protective $\beta$ chemokines, CCL3 (MIP-1 $\alpha$ ), CCL4 (MIP-1 $\beta$ ) and CCL5 (RANTES). Data presented in Fig. 3 show a dose response effect of Meth on CCL3 (MIP-1 $\alpha$ ) and CCL4 (MIP-1 $\beta$ ) gene expression by MDC. Meth at 10 (TAI $=1.0, \mathrm{p}=\mathrm{NS}), 25(\mathrm{TAI}=0.8, \mathrm{p}=\mathrm{NS}), 50(\mathrm{TAI}=0.6$, $\mathrm{p}<0.01,35 \%$ decrease), and $100 \mu \mathrm{M}$ (TAI $=0.5$, $\mathrm{p}<0.01,44 \%$ decrease) show a dose dependent decrease of CCL3 gene expression compared to the untreated control $(\mathrm{TAI}=1.0)$. Similarly, Meth at $10(\mathrm{TAI}=1.0$, $\mathrm{p}=\mathrm{NS}), 25(\mathrm{TAI}=0.78, \mathrm{p}=0.03,22 \%$ decrease $), 50$ (TAI $=0.70, p<0.03,30 \%$ decrease), and $100 \mu \mathrm{M}$ (TAI $=0.53, \mathrm{p}<0.01,47 \%$ decrease)

show a dose dependent inhibition of CCL4 gene expression compared to the untreated control $(\mathrm{TAI}=$ 1.0). These results demonstrate selective inhibition of CCL3 and CCL4 genes and rule out the possibility of non-specific toxic effects as expression of the housekeeping gene was not affected by Meth. Further Meth at $10-100 \mu \mathrm{M}$ did not induce apoptosis by DC as assessed by Annexin V expression by FACS analysis (Fig. $2 b$ ) as well as evidenced by $>95 \%$ viability by trypan blue dye exclusion (results not provided).

Since previous studies show that a RANTES (CCL5) variant, In1.1c, has been associated with accelerated HIV-1 disease progression ${ }^{[26,40,24]}$, we examined the in vitro effect of Meth on total RANTES and its variant, In1.1c, gene expression by both IDC and MDC. Data presented in Fig. 4 show that Meth significantly inhibited total RANTES gene expression in a dose dependent manner by both IDC and MDC; whereas RANTES variant In1.1c was significantly upregulated in a dose dependent manner by both IDC and MDC. Using real time PCR, we also quantified the gene expression of total RANTES and its variant In1.Ic by MDC from 3 normal subjects and age and sex matched 3 HIV-1 infected subjects (Fig. 5a and 5b). Results (Fig. 5c) show that in HIV-1 infected subjects, the mean RANTES gene expression (TAI $=3.1$, $\mathrm{p}<0.001)$ was significantly lower $(40 \%$ suppression) than the normal controls $(\mathrm{TAI}=5.2)$ while the RANTES variant In1.1c gene expression was significantly higher (147\% increase) in the HIV-1 infected subjects $(\mathrm{TAI}=7.3, \mathrm{p}<0.003)$ compared to the normal controls $(\mathrm{TAI}=2.9)$. Data presented in Fig. 6 show that Meth significantly suppressed the endogenous production of CCL4 and CCL5 by normal MDC in a dose dependent manner.

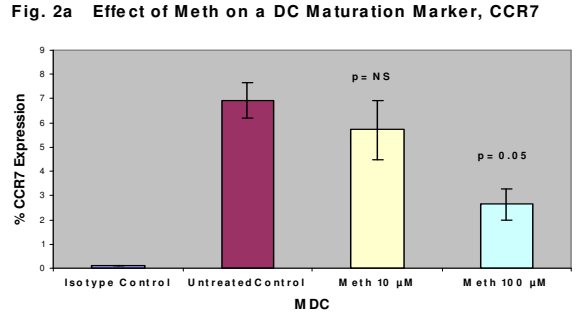

Fig. 2a: Meth inhibits MDC maturation by decreasing the expression of CCR7. 2a: MDC $\left(\sim 5 \mathrm{X} 10^{5}\right.$ cell $/ \mathrm{ml}$ ) were treated with Meth for $24 \mathrm{hr}$ following which FACS analysis was done to determine the percentage of cells expressing CCR7. Statistical significance was calculated by Students' ' $\mathrm{t}$ '-test $(\mathrm{n}=3)$.

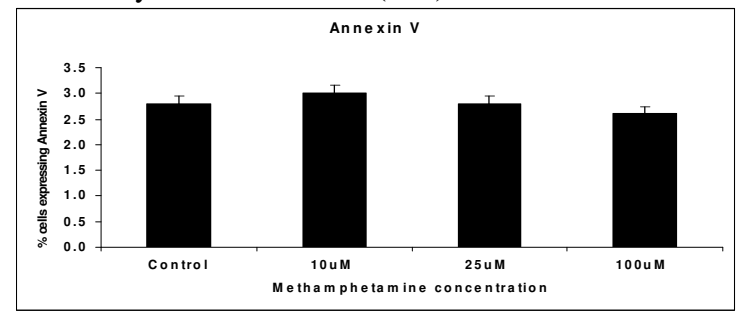

Fig.2b: Effect of Methamphetamine on cell viability using Annexin V staining. 2b: Cells are stained with PE (Phycoerythrin ) labeled Annexin $\mathrm{V}$ and percentage of cells stained with Annexin V are analyzed using Flow cytometric analysis. The percentage of cells expressing annexin $\mathrm{V}$ for the untreated control, 10, 25 and 100uM methamphetamine treated cultures are $2.8+0.36,3.0+$ $0.10,2.76+0.35$, and $2.56+0.15$ respectively. These data are mean + SD from 3 separate experiments.

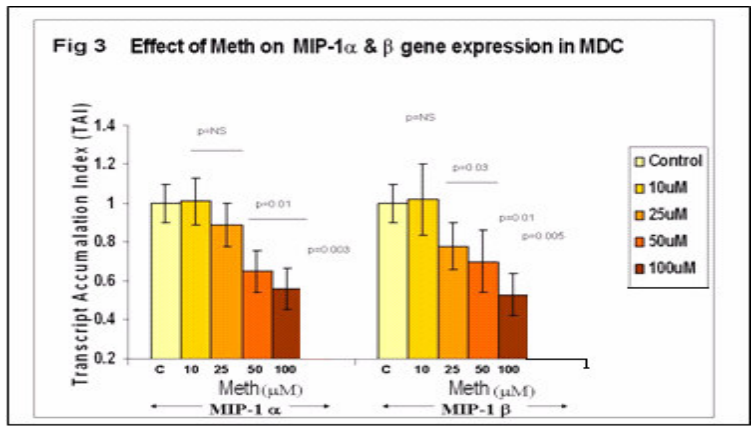

Fig.3: $\quad$ Meth down regulates MIP-1 $\square$ and $\square$ gene expression in MDC. MDC $\left(\sim 5 \times 10^{5}\right.$ cell $\left./ \mathrm{ml}\right)$ were cultured with and without Meth (10- $100 \square$ M) for $24 \mathrm{hr}$, RNA was extracted and reverse transcribed followed by quantitative real time PCR for MIP-1 $\square$ and MIP-1 $\square$ and housekeeping genes ( $\square$-actin) primers. The data represents the mean $+\mathrm{SD}$ of 3 independent experiments. Statistical significances between controls and treated samples was calculated by Students' 't'-test $(n=3)$. 
Am. J. Infect. Dis., 3 (4): 217-224, 2007

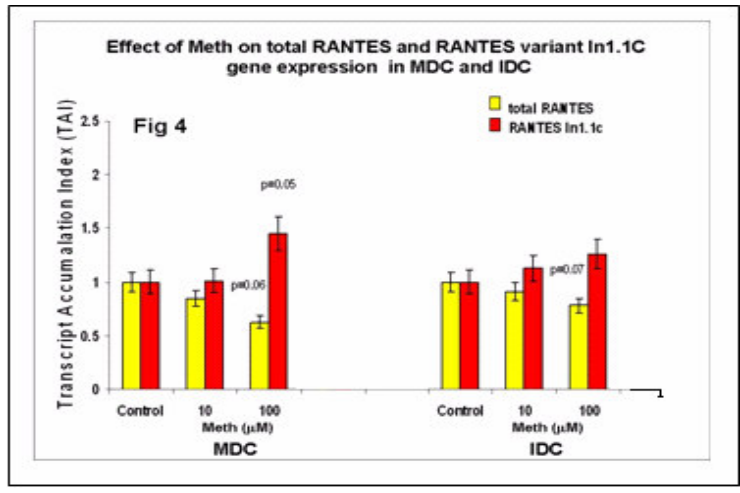

Fig. 4 Meth downregulates total RANTES and upregulates RANTES variant In1.1c gene expression in IDC and MDC. MDC and IDC from normal subjects $\left(\sim 5 \times 10^{5}\right.$ cell/ml) were cultured with Meth $(10 \& 100 \square \mathrm{M})$ for $24 \mathrm{hr}$, RNA was extracted and reverse transcribed followed by quantitative real time PCR for total RANTES and RANTES variant In1.1c and house keeping gene $\square$-actin. The data represents the mean + $\mathrm{SD}$ of 3 independent experiments. Statistical significance was calculated by Students' 't'-test $(n=3)$.

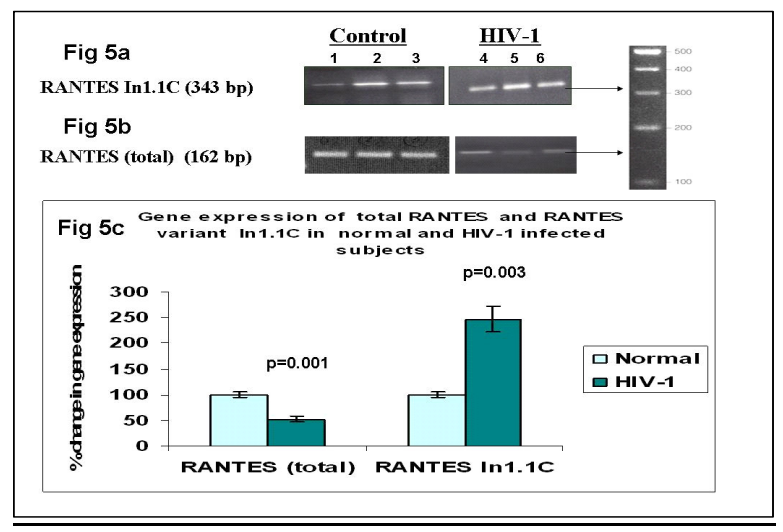

Fig. 5: HIV-1 seropositive patients demonstrate a lower level of total RANTES and a higher level of RANTES variant In1.1c. RNA from the MDC from normal subjects and HIV-1 patients were reverse transcribed followed by quantitative real time PCR against total RANTES and RANTES variant In1.1c primers. The amplified QPCR products were electrophorised on a $1.2 \%$ agarose gel containing ethidium bromide to confirm the size of the RANTES variant In1.1c and total RANTES as shown in Fig. 5a and 5b respectively; Lanes 1-3 are normal controls and Lanes 4-6 are HIV-1 infected subjects from a representative experiment. Fig. 5c Shows the mean + SD of data from 9 different subjects. Statistical significance between the expression levels in HIV-1 and normal controls was calculated by Students' ' $\mathrm{t}$ 'test $(n=9)$.

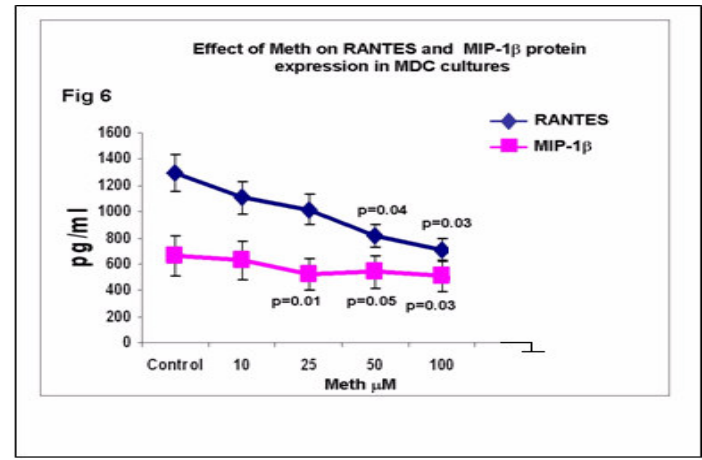

Fig. 6: Meth suppresses endogenous production of RANTES and MIP-1 $\square$. MDC from normal subjects were cultured with Meth (10-100 $\square \mathrm{M})$ for $72 \mathrm{hr}$ and the RANTES and MIP-1 $\square$ levels in the culture supernatants were measured by ELISA $(n=3)$ (Biosource Inc, CA). The data represents the mean + SD of 3 independent experiments. Statistical significance was determined by Students' ' $t$ '- test.

\section{DISCUSSION}

US is currently experiencing a grave epidemic of Meth use as a recreational drug and recent studies show a high prevalence of HIV-1 infection among Meth users ${ }^{[41-45]}$. The important role of DC as the first line of defense against HIV-1 infection has recently been recognized. $\beta$-chemokines have gained major attention recently because of their specific inhibitory effects on HIV-1 infection ${ }^{[7-8]}$. Previous studies show that DC produce a number of cytokines and chemokines that are essential for $\mathrm{T}$ cell differentiation and clonal expansion ${ }^{[27-28]}$. While the capacity of DC to migrate is regulated by the expression of a number of cytokines and chemokines, further activation is regulated by various co stimulatory molecules. Our previous studies show that the number of MDC expressing co stimulatory molecules (CD86, CD 83 and CD80) is significantly lower in polydrug using HIV-1 infected patients compared to non-using HIV-1 infected subjects ${ }^{[46]}$. In the present report we demonstrate that Meth downregulates the expression of co stimulatory molecule, CD83 (Fig. 1) and the DC maturation marker, CCR7 (Fig. 2) by DC. Since $\beta$-chemokines are natural ligands for HIV-1 co-receptors and play significant role in blocking of HIV-1 infection, our finding that Meth downregulates the HIV-1 suppressing chemokines by DC further support the premise that increased HIVdisease progression in Meth using patients may be via down regulation of these protective chemokines. Further HIV-1 infected patients demonstrate decreased gene expression of the HIV-1 suppressing chemokine 
RANTES, while a genetic variant of RANTES, In1.1C, which is reported to be associated with accelerated disease progression ${ }^{[26,40,24]}$, has been found to be elevated (Fig. 5) compared to control subjects. In our in vitro model using both IDC and MDC, Meth also showed significant inhibition of $\beta$-chemokines and a reciprocal upregulation of RANTES variant.

Based on these findings, it is possible that, Meth use by HIV-1 positive patients may suppress costimulatory molecules, DC maturation markers and the production of HIV-1 suppressing chemokines with a reciprocal upregulation of RANTES variant, all of which may lead to progression of HIV-1 disease. The findings that Meth inhibits HIV-1 suppressing chemokines such as CCL3, CCL4, and CCL5 will help to support the therapeutic application of these chemokines to restore anti-HIV-1 immune responses to control HIV-1 infection. These include the replacement of chemokines and co stimulatory molecules downregulated by Meth with recombinant products and use of antisense oligonucleotides and siRNA against RANTES variant. Thus our studies may help to develop novel strategies for preventing and treating HIV-1 infections particularly in high risk populations such as Meth users.

\section{REREFERENCES}

1. National Survey on Drug Use and Health (U.S.), United States. Substance Abuse and Mental Health Services Administration. Office of Applied Studies, 2005. Results from the 2004 National Survey on Drug Use and Health: national findings. Dept. of Health and Human Services Substance Abuse and Mental Health Services Administration Office of Applied Studies, Rockville, MD.

2. Song, X.T, Evel-Kabler K, Rollins L, Aldrich M, Gao F, Huang XF, and Chen SY., 2006. An alternative and effective HIV vaccination approach based on inhibition of antigen presentation attenuators in dendritic cells. PLoS Med., 3: e11.

3. Groot, F., Kuijpers TW, Berkhout B, and de Jong EC., 2006. Dendritic cell-mediated HIV-1 transmission to $\mathrm{T}$ cells of LAD-1 patients is impaired due to the defect in LFA-1. Retrovirology., 3:75.

4. Buonaguro, L., Tornesello ML, Tagliamonte M, Gallo RC, Wang LX, Kamin-Lewis R, Abdelwahab S, Lewis GK, and Buonaguro FM., 2006. Baculovirus-derived human immunodeficiency virus type 1 virus-like particles activate dendritic cells and induce ex vivo T-cell responses. J Virol., 80: 9134- 9143.
5. Hart, D.N., 1997. Dendritic cells: unique leukocyte populations which control the primary immune response. Blood., 90: 3245-3287.

6. Steinman, R.M., and R.N. Germain, 1998. Antigen presentation and related immunological aspects of HIV-1 vaccines. AIDS., 12 S A: S97-112.

7. Lusso, P., 2002. HIV and chemokines: implications for therapy and vaccine. Vaccine., 20: 1964-1967.

8. Verani, A., and P. Lusso, 2002. Chemokines as natural HIV antagonists. Curr. Mol. Med., 2: 691702.

9. Alkhatib, G., C. Combadiere, C.C. Broder, Y. Feng, P.E. Kennedy, P.M. Murphy, and E.A. Bergert, 1996. CC CKR5: A RANTES, MIP-1 $\alpha$, MIP-1 $\beta$ receptor as a fusion cofactor for macrophage-tropic HIV- 1. Science., 272: 19551958.

10. Friedman, H., Pross S, and Klein TW., 2006.Addictive drugs and their relationship with infectious diseases. FEMS Immunol. Med. Microbiol., 47:330-342.

11. Sacerdote, P., 2006. Opioids and the immune system. Palliat. Med., 20 (Suppl 1):s9-15.

12. Makman, MH., 1994. Morphine receptors in immunocytes and neurons. Adv. Neuroimmunol., 4:69-82.

13. Chougnet, C., S.S. Cohen, T. Kawamura, A.L. Landay, H.A. Kessler, E. Thomas, A. Blauvelt, and G.M. Shearer, 1999. Normal immune function of monocyte-derived dendritic cells from HIVinfected individuals: implications for immunotherapy. J. Immunol., 163: 1666-1673.

14. Fanales-Belasio, E., S. Moretti, F. Nappi, G. Barillari, F. Micheletti, A. Cafaro, and B. Ensoli, 2002. Native HIV-1 Tat protein targets monocytederived dendritic cells and enhances their maturation, function, and antigen-specific $\mathrm{T}$ cell responses. J. Immunol., 168: 197-206.

15. Folcik, R.M., J.D. Merrill, Y. Li, C.J. Guo, S.D. Douglas, S.E. Starr, and W.Z. Ho, 2001. HIV-1 infection of placental cord blood monocyte-derived dendritic cells. J. Hematother. Stem Cell Res., 10: 609-620.

16. Lejeune, M., F. García, C. Gil, J. Alcami, J. Joseph, J. Miró, M. Plana, J.M. Gatell, and T. Gallart, 2002. Generation of Monocyte-Derived Dendritic Cells (MD-DC) in Clinical GMP Conditions and their Ability to Activate CD4 and CD8 T Cells to HIV Antigens in Early HIV+ Individuals Receiving HAART. Abstract in 9th Conference on Retroviruses and Opportunistic Infections. 
17. Mallon, D.F., A. Buck, J.C. Reece, S.M. Crowe, and P.U. Cameron, 1999. Monocyte-derived dendritic cells as a model for the study of HIV-1 infection: productive infection and phenotypic changes during culture in human serum. Immunol. Cell Biol., 77: 442-450.

18. McDonald, D., L. Wu, S.M. Bohks, V.N. KewalRamani, D. Unutmaz, and T.J. Hope, 2003. Recruitment of HIV and its receptors to dendritic cell-T cell junctions. Science., 300: 1295-1297.

19. Patterson, S., M.S. Roberts, N.R. English, S.E. Macatonia, M.N. Gompels, A.J. Pinching, and S.C. Knight, 1994. Detection of HIV DNA in peripheral blood dendritic cells of HIV-infected individuals. Res. Virol., 145: 171-176.

20. Perumal, D., 2001. Micro encapsulation of ibuprofen and Eudragit RS 100 by the emulsion solvent diffusion technique. Int. J. Pharm., 218: 1-11.

21. Toujas, L., J.G. Delcros, E. Diez, N. Gervois, G. Semana, G. Corradin, and F. Jotereau, 1997. Human monocyte-derived macrophages and dendritic cells are comparably effective in vitro in presenting HLA class I-restricted exogenous peptides. Immunology., 91: 635-642.

22. Tsunetsugu-Yokota, Y., K. Akagawa, H. Kimoto, K. Suzuki, M. Iwasaki, S. Yasuda, G. Hausser, C. Hultgren, A. Meyerhans, and T. Takemori, 1995. Monocyte-derived cultured dendritic cells are susceptible to human immunodeficiency virus infection and transmit virus to resting $\mathrm{T}$ cells in the process of nominal antigen presentation. J. Virol., 69: 4544-4547.

23. Turville, S.G., J. Arthos, K.M. Donald, G. Lynch, H. Naif, G. Clark, and D. Hart, 2001. HIV gp120 receptors on human dendritic cells. Blood., 98: 2482-2488.

24. Liu, H., D. Chao, E.E. Nakayama, H. Taguchi, M. Goto, X. Xin, J.K. Takamatsu, H. Saito, Y. Ishikawa, T. Akaza, T. Juji, Y. Takebe, T. Ohishi, K. Fukutake, Y. Maruyama, S. Yashiki, S. Sonoda, T. Nakamura, Y. Nagai, A. Iwamoto, and T. Shioda, 1999. Polymorphism in RANTES chemokine promoter affects HIV-1 disease progression. Proc. Natl. Acad. Sci. USA., 96: 4581-4585.

25. Wichukchinda, N., E.E. Nakayama, A. Rojanawiwat, P. Pathipvanich, W. Auwanit, S. Vongsheree, K. Ariyoshi, P. Sawanpanyalert, and T. Shioda, 2006. Protective Effects of IL-589 T and RANTES-28G on HIV-1 disease progression in infected Thai females. AIDS, 20: 189-196.
26. An, P., G.W. Nelson, L. Wang, S. Donfield, J.J Goedert, J. Phair, D. Vlahov, S. Buchbinder, W.L. Farrar, W. Modi, S.J. O'Brien, and C.A. Winkler, 2002. Modulating influence on HIV/AIDS by interacting RANTES gene variants. Proc. Natl. Acad. Sci. USA., 99:10002-7.

27. Banchereau, J., and R.M. Steinman, 1998. DC and the control of immunity. Nature., 392: 245-252.

28. Cella, M., and A. Engering, V. Pinet, J. Pieters, and A. Lanzavecchia, 1997. Inflammatory stimuli induce accumulation of MHC class II complexes on DC. Nature., 388: 782-787.

29. Cao, H., V. Verge, C. Baron, C. Martinache, A. Leon, S. Scholl, N.C. Gorin, J. Salamero, S. Assari, J. Bernard, and M. Lopez, 2000. In vitro generation of dendritic cells from human blood monocytes in experimental conditions compatible for in vivo cell therapy. J. Hematother. Stem Cell Res., 9:183-194.

30. Caux, C., C. Massacrier, B. Vanbervliet, B. Dubois, C. Van Kooten, I. Durand, and J. Banchereau, 1994. Activation of human DC through CD40 cross-linking. J. Exp. Med., 180:1263-1272.

31. Caux, C., 1998. Pathways of development of human dendritic cells. Eur. J. Dermatol., 8: 375-384.

32. Caux, C., S. Ait-Yahia, K. Chemin, O. de Bouteiller, M.C. Dieu-Nosjean, B. Homey, C. Massacrier, B. Vanbervliet, A. Zlotnik, and A. Vicari, 2000. Dendritic cell biology and regulation of dendritic cell trafficking by chemokines. Springer Seminars in Immunopathology., 22:345369.

33. Sallusto, F., B. Palermo, D. Lenig, M. Miettinen, S. Matikainen, I. Julkunen, R. Forster, R. Burgstahler, M. Lipp, and A. Lanzavecchia, 1999. Distinct patterns and kinetics of chemokine production regulate dendritic cell function. Eur. J. Immunol., 29: 1617-1625.

34. Yanagihara, S., E. Komura, J. Nagafune, H. Watarai, and Y. Yamaguchi, 1998. EBI1/CCR7 is a new member of dendritic cell chemokine receptor that is up-regulated upon maturation. J. Immunol., 161: 3096-3102.

35. Dauer, M., B. Obermaier, J. Herten, C. Haerle, K. Pohl, S. Rothenfusser, M. Schnurr, S. Endres, and A. Eigler, 2003. Mature dendritic cells derived from human monocytes within 48 hours: a novel strategy for dendritic cell differentiation from blood precursors. J. Immunol., 170: 4069-4076.

36. Schepers, RJF., Oyler JM, Joseph RE, Cone EJ, Moolchan ET, and Huestis, MA.., 2003. Methamphetamine and amphetamine pharmacokinetics in oral fluid and plasma after controlled oral methamphetamine administration to human volunteers. Clin. Chem., 49: 121-132. 
37. Takayasu, T, Ohshima T, Nishigami J, Kondo T, and Nagaon, T., 1995. Screening and determination of methamphetamine and amphetamine in the blood, urine and stomach contents in emergency medical care and autopsy cases. J. Clin. Forensic med., 2: 25-33.

38. Chomczynski, P., and Sacchi, N., 1987. Single-step method of RNA isolation by acid guanidinium thiocyanate-phenol-chloroform extraction. Anal. Biochem., 162:156-159.

39. Shively, L, Chang L, LeBon JM, Liu Q, Riggs AD, and Singer-Sam, J., 2003. Real-time PCR assay for quantitative mismatch detection. Biotechniques., 34:498-502, 504.

40. Duggal, P., C.A. Winkler, P. An, X.F. Yu, H. Farzadegan, S.J. O'Brien, T.H. Beaty, and D. Vlahov, 2005. The effects of RANTES chemokine genetic variants on Early HIV-1 plasma RNA among African American injection drug users. J. Acquir. Immune. Defic. Syndr., 38: 584-589.

41. Anonymous., 2005. HIV \& Drugs: Meth use develops stronger link to HIV risk. AIDS Policy Law., 20: 5.

42. Boddiger, D., 2005. Methamphetamine use linked to rising HIV transmission. Lancet., 365:12171218.
43. Frosch, D, Shoptaw S, Huber A, Rawson RA, and Ling W., 1996. Sexual HIV risk among gay and bisexual male methamphetamine abusers. J. Subst. Abuse Treat., 13: 483-486.

44. Halkitis, P.N., Parsons, J.T., and Stirratt, M.J., 2001. A Double Epidemic: Crystal Methamphetamine Drug Use in Relations to HIV Transmission Among Gay Men. J. Homosexuality., 41:17-35.

45. Urbina, A, and Jones K., 2004. Crystal methamphetamine, its analogues, and HIV infection: medical and psychiatric aspects of a new epidemic. Clin. Infect. Dis., 38: 890-894.

46. Nair, M.P., S.D. Mahajan, S.A. Schwartz, J. Reynolds, R. Whitney, Z. Bernstein, R.P. Chawda, D. Sykes, R. Hewitt, and C.B. Hsiao, 2005. Cocaine modulates dendritic cell-specific $\mathrm{C}$ type intercellular adhesion molecule-3-grabbing 